\title{
Identidade volitiva: a contribuição de Fichte para a explicitação do conceito de pessoa
}

\author{
$\frac{\text { Christian Klotz }}{\text { Professor Doutor do Departamento }}$ \\ de Filosofia da UFSM
} Resumo: Na sua Doutrina da Ciência
nova methodo, Fichte defende que só
ao identificar-se com uma determi-
nação volitiva que submete as suas
ações sob uma exigência 'categórica',
um sujeito alcança uma determinada
concepção de si. O artigo presente
tem por objetivo mostrar que esta
tese fichtiana envolve uma noção
de identidade volitiva que anteci-
pa concepções contemporâneas da
identidade prática de pessoas, tal
como têm sido sugeridas por H.
Frankfurt e Chr. Korsgaard.

Palavras-Chave: Fichte, Autoconsciência, Identidade prática

\begin{abstract}
In The Science of Knowledge nova methodo, Fichte holds that a subject only acquires a determinated conception of itself by identifying itself with a volitional determination that subjects its actions to a categorical "ought to". The present article aims at showing that the fichtean thesis encompasses a conception of volitive identity which anticipates contemporary conceptions of the practical identity of persons, such as those introduced by $\mathrm{H}$. Frankfurt and Chr. Korsgaard.
\end{abstract}

Keywords: Fichte, Self-Consciousness, Practical identity

No seu período ienense, Fichte desenvolveu um tipo próprio de argumentação transcendental. Neste, as estruturas da nossa experiência e do nosso agir são legitimadas ao serem estabelecidas como condições da auto-referência pela qual compreendemos a nós mesmos como sujeitos espontâneos. Obviamente, esta estratégia pressupõe uma determinada concepção da auto-referência, cujas condições são analisadas, que serve como ponto de partida - como "princípio" - da argumentação. No entanto, Fichte não acreditava que o modo como nós originalmente nos referimos a nós mesmos está, por assim dizer, imediatamente diante de nossos olhos. Em vez disso, ele defendeu que ele está escondido por 
autoconcepções secundárias. Portanto, parecia-lhe necessário usar argumentos e análises filosóficos já no contexto da formulação do princípio do seu sistema. A chamada Doutrina da Ciência nova methodo, que Fichte apresentou em Iena a partir de 1796, leva extensamente em conta este ponto, pois na sua maior parte ela consiste numa argumentação ascendente que serve para estabelecer o princípio da Doutrina da Ciência. ${ }^{1}$

O resultado dessa argumentação é que a nossa auto-referência fundamental é essencialmente prática. Ela consiste no fato de que identificamos a nós mesmos com a "vontade pura". No entanto, esta autoconcepção original já envolve normatividade; pois a determinação pura da vontade, com a qual identificamos a nós mesmos, constitui uma exigência “categórica” à qual nós, enquanto agentes, estamos submetidos. Assim, no seu argumento ascendente para o princípio da Doutrina da Ciência, Fichte estabelece um resultado que se aproxima de abordagens mais recentes sobre a auto-referência de pessoas, tais como as que têm sido defendidas por H. Frankfurt e Chr. Korsgaard. Em particular, Fichte já antecipa a tese de que a identidade de pessoas está intrinsecamente ligada à normatividade. Ao menos é isso o que se defenderá no que segue: o propósito principal desta exposição será mostrar que Fichte, na argumentação fundamental da Doutrina da Ciência nova methodo, descobriu a identidade normativa de pessoas como um assunto próprio da investigação filosófica. Se esta tese for correta, pode-se dizer que Fichte reconstruiu um pressuposto implícito da ética kantiana, que se baseia na concepção da identidade normativa de pessoas sem torná-la um assunto da investigação explícita. ${ }^{2}$

1. Esta exposição, que substitui o Fundamento de toda a Doutrina da Ciência (1794/95) e que foi apresentada três vezes entre 1796 e 1799, não foi publicada por Fichte como um todo. A principal fonte considerada no que segue é o manuscrito do seu ouvinte K. Chr. Fr. Krause. Fichte, J. G. Wissenschaftslehre nova methodo. Kollegnachschrift K. Chr. Fr. Krause. Org. de E. Fuchs. Hamburgo: F. Meiner, 1982.

2. Cf. a terceira seção da Fundamentação da Metafísica dos Costumes, em que Kant afirma que o "eu verdadeiro" está intrinsecamente ligado à lei moral. Kant, I. Fundamentação da Metafísica dos Costumes. Trad. de Paulo Quintela. Lisboa: Edições 70, 2007, p. 135. 
A seguinte exposição se dividirá em três partes: primeiro, será apresentado o contexto sistemático no qual Fichte introduz a concepção da auto-referência prática de pessoas na Doutrina da Ciência nova methodo. Na segunda parte será reconstruída a argumentação pela qual Fichte estabelece o conceito de identidade normativa como uma concepção fundamental para a compreensão do conceito de pessoa. Por fim, a relação entre a contribuição de Fichte e a discussão contemporânea sobre o conceito de pessoa - em particular a influente posição de Harry Frankfurt - será discutida.

\section{Da consciência imediata à reflexão: $\mathrm{O}$ contexto sistemático da introdução do conceito de identidade normativa em Fichte}

No primeiro parágrafo da Doutrina da Ciência nova methodo, Fichte pretende mostrar que a referência consciente a objetos é possibilitada por uma consciência de si cuja natureza difere fundamentalmente de qualquer referência objetiva. ${ }^{3}$ Fichte parte em seu argumento da observação de que a referência a objetos e, com isso, qualquer consciência intencional, surge de uma atividade espontânea. É a atividade referencial da consciência que determina o que é o seu objeto. Esta atividade, o "pensar" no seu sentido mais fundamental, pode ser exercida de dois modos diferentes, que Fichte caracteriza metaforicamente como "direções" do pensar: podemos referir-nos a nós mesmos, ou a coisas que distinguimos de nós. No entanto, em qualquer caso - e isso é a tese principal de Fichte - a consciência intencional é possibilitada por uma consciência que é de um outro caráter do que a exercida em referência ao objeto. Assim, o "eu" que subjaz a toda consciência intencional está "na consciência", mas de uma maneira diferente daquela que caracteriza um objeto

3. Cf. Fichte, J. G. Wissenschaftslehre nova methodo. Kollegnachschrift K. Chr. Fr. Krause, pp. 28-35. Fichte expôs o argumento do primeiro parágrafo da Doutrina da Ciência nova methodo também no Ensaio de uma nova exposição da Doutrina da Ciência, de 1797, que foi concebido como primeiro capítulo da publicação de toda a Doutrina da Ciência nova methodo, plano que não foi realizado por Fichte. Cf. Fichte, J. G. A Doutrina-Da-Ciência de 1794 e Outros Escritos. Trad. de Rubens Rodrigues Torres Filho. São Paulo: Abril Cultural, 1984, pp. 177-85. 
pensado, seja este um objeto da experiência interna ou externa. Por isso, Fichte caracteriza o modo como o eu está originalmente consciente como uma autoconsciência "imediata".

No argumento para essa tese dois passos podem ser distinguidos. Primeiro, Fichte introduz a concepção de uma consciência pré-reflexiva dos atos de pensar, pela qual estamos conscientes destes atos ao exercê-los, antes de qualquer pensamento de segunda ordem que os torne um objeto explícito do pensamento. A consciência imediata do pensar, incluída já na perspectiva do seu exercício, é uma condição da consciência de qualquer objeto que necessariamente envolve uma consciência do ato espontâneo pelo qual este é fixado como objeto. ${ }^{5}$ No entanto, este resultado ainda não envolve a tese, decisiva para Fichte, de que a consciência préreflexiva já envolve uma consciência de si como sujeito do pensamento, em vez de apresentar atos "anônimos" do pensamento sem sujeito. É neste ponto que a argumentação de Fichte entra no terreno próprio da teoria da consciência de si. Assim, no seu primeiro passo, a abordagem fichtiana sobre a autoconsciência pertence ao contexto de uma investigação da consciência intencional e das suas condições: Fichte pretende mostrar que a forma fundamental da consciência de si está situada naquela consciência pré-reflexiva do pensamento que subjaz a qualquer consciência de objetos. ${ }^{6}$

Esse objetivo exige refutar uma imagem da autoconsciência que inicialmente parece muito plausível: a noção segundo a qual a consciência de si, na sua forma fundamental, surge do ato no qual

4. Cf. Fichte, J. G. Wissenschaftslehre nova methodo. Kollegnachschrift K. Chr. Fr. Krause, p. 34; e __. Ensaio de uma nova exposição da Doutrina da Ciência. In: __ A Doutrina-Da-Ciência de 1794 e Outros Escritos, pp. 177 e 182.

$\mathrm{Na}$ preleção, Fichte dá a seguinte formulação da tese a ser demonstrada: "Toda a consciência é acompanhada por uma autoconsciência imediata, e é só sob a pressuposição desta que se pensa”. Fichte, J. G. Wissenschaftslehre nova methodo. Kollegnachschrift K. Chr. Fr. Krause, p. 34, tradução do autor.

5. Cf. Fichte, J. G. Ensaio de uma nova exposição da Doutrina da Ciência. In: . A Doutrina-Da-Ciência de 1794 e Outros Escritos, p. 182.

6. Para uma interpretação da concepção fichtiana que destaca o aspecto da sua vinculação com a teoria da consciência intencional, cf. Neuhouser, F. Fichte's Theory of Subjectivity. Cambridge: Cambridge University Press, 1990, pp. 68 ss. 
um sujeito se torna um objeto do seu pensamento. Segundo esta imagem, a autoconsciência é apenas uma espécie particular da referência a um objeto, e não uma consciência de caráter diferente que subjaz a qualquer consciência intencional. O conhecido argumento do círculo, que se encontra no primeiro parágrafo da Doutrina da Ciência nova methodo e no Ensaio, tem justamente a função de mostrar que esta imagem, a concepção da autoconsciência como surgindo originalmente de um ato de "reflexão", é inadequada. $\mathrm{O}$ argumento baseia-se na observação de que um sujeito, ao tornarse objeto do seu pensamento, só pode alcançar uma consciência de si através deste ato na medida em que já possui algum tipo de autoconsciência. Pois a reflexão exige, ao lado do sujeito que reflete, a consciência de que o objeto do seu pensamento é idêntico a si mesmo enquanto sujeito pensante. Se a autoconsciência pressuposta na reflexão fosse explicada novamente a partir de um ato de reflexão, um regresso infinito na explicação da autoconsciência seria inevitável. ${ }^{7}$

O conceito de "intuição intelectual", introduzido no primeiro parágrafo da Doutrina da Ciência nova methodo, tem de ser entendido a partir desse argumento: ele serve para explicitar o caráter particular daquela consciência de si pré-reflexiva que subjaz a qualquer consciência intencional. Esta é "intelectual" no sentido de que surge espontaneamente na consciência. $O$ conceito de "intuição", entretanto, refere-se aqui a três características diferentes da autoconsciência pré-reflexiva. Primeiro, ao aspecto de que nesta autoconsciência o sujeito pensante está presente. Assim, o "eu" préreflexivamente consciente não é um objeto que pode ser distinguido do seu estar consciente, sendo independente disso; o "eu" existe apenas no sentido de que é o conteúdo da autoconsciência pré-reflexiva. No entanto, a caracterização como "intuição" serve

7. Cf. Fichte, J. G. Wissenschaftslehre nova methodo. Kollegnachschrift K. Chr. Fr. Krause, p. 30; e ___. Ensaio de uma nova exposição da Doutrina da Ciência. In: _. A Doutrina-Da-Ciência de 1794 e Outros Escritos, pp. 181-2. Cf. a discussão influente do argumento em Henrich, D. "Fichtes ursprüngliche Einsicht”. In: Cramer, W.; ___.(orgs.). Subjektivität und Metaphysik. Frankfurt: V. Klostermann, 1966, pp. 188-232. 
também para destacar um outro aspecto da autoconsciência imediata: como a intuição sensível, enfatiza Fichte, a intuição intelectual não é "nenhuma consciência completa", isto é, não constitui por si um estado consciente. Ela só ocorre como "condição e parte de uma outra consciência", a saber, de uma consciência intencional. ${ }^{8}$ Assim, o conceito de intuição serve também para expressar a incompletude da autoconsciência imediata. Finalmente, o conceito de "intuição" tem a função de destacar a ausência de diferenciação como um aspecto da autoconsciência imediata. Determinação conceitual e diferenciação individual são apenas possíveis no pensamento e, com isso, em relação com objetos. A autoconsciência imediata é "intuição" também no sentido de que ela ainda não envolve tais atos epistêmicos. Nela, o "eu" consciente não é compreendido como o que é, nem é individualizado, isto é, distinguido como sujeito singular de outros sujeitos.

O resultado estabelecido implica que a autoconsciência imediata ainda não inclui aquela auto-referência que nos caracteriza como pessoas, pois esta envolve a formação da uma autoconcepção, isto é, de uma compreensão da própria identidade. É verdade que a autoconsciência "imediata", que está envolvida na consciência intencional como tal, é a autoconsciência originária, sendo uma pressuposição de qualquer concepção de si que surge da reflexão. Mas ela ainda não fornece aquela referência a si que constitui pessoas como tais. Por isso, Fichte diz que o "eu" tem de superar a mera autoconsciência pré-reflexiva e tornar-se um "objeto" do seu pensamento. ${ }^{9}$ Esta passagem da autoconsciência imediata para a reflexão, decisiva para toda a estrutura da Doutrina da Ciência nova methodo, não pode ser entendida como dizendo que um sujeito necessariamente forma uma autonconcepção, de modo que a subjetividade necessariamente dá origem à personalidade. A consciência intencional e a autoconsciência imediata nela envolvida não implicam a

8. Cf. o manuscrito "Neue Bearbeitung der Wissenschaftslehre" de 1800, em: Fichte, J. G. Gesamtausgabe der Bayerischen Akademie der Wissenschaften. vol. II/5. Stuttgart: Frommann-Holzboog, 1962, p. 338.

9. Cf. Fichte, J. G. Wissenschaftslehre nova methodo. Kollegnachschrift K. Chr. Fr. Krause, pp. 38 e 49. 
necessidade de uma reflexão e da formação de uma autoconcepção a partir dela. Em vez disso, a formulação fichtiana marca a transição para uma questão ampliada, a passagem da investigação da autoconsciência, que é necessária para qualquer consciência intencional, para uma abordagem sobre a auto-referência que é constitutiva de pessoas. Assim, Fichte volta-se aqui para o ponto de vista próprio do ser pessoal, que pressupõe a intencionalidade consciente, mas ainda não está estabelecido com esta.

\section{A Identidade normativa como condição da auto-referência prática}

A questão norteadora dos passos que se seguem ao primeiro parágrafo da Doutrina da Ciência nova methodo é a de como é possível a consciência de um "si", isto é, de si mesmo como objeto da reflexão. Nessa abordagem, Fichte parte de uma dualidade fundamental para a reflexão: um "si" é um objeto real, que é capaz de efetividade causal; ao mesmo tempo, ele é tal que um sujeito consciente se identifica com ele. Neste sentido, "realidade" e "idealidade" são aspectos fundamentais de um "si". ${ }^{10}$ Segundo Fichte, isso implica o caráter prático-volitivo do "si", pois a efetividade real só pode ser entendida como atividade própria na medida em que se baseia no pensamento, isto é, em atos intencionais que se referem a objetos. Isso se segue do primeiro parágrafo da exposição, cujo resultado é que a autoconsciência original é uma consciência pré-reflexiva de si como sujeito de atos intencionais. Assim, um "si" tem de ser "inteligência". Mas, ao mesmo tempo, o status do "si" como objeto exige que sua intencionalidade seja ligada à efetividade real. Portanto, o seu pensar tem de ser um conceber de fins, iniciando ações (de ante-imagens, e não de pós-imagens, como Fichte o expressa). No entanto, isso significa que um "si", em primeiro lugar, tem de ser concebido como "querendo", como sujeito volitivo: possuir uma concepção de si signfica entrar numa auto-referência prática. ${ }^{11}$

10. Cf. Idem, p. 48.

11. Cf. Idem, pp. 52-5. Cf. Stolzenberg, J. "Fichtes Begriff des praktischen Selbstbewusstseins”. In: Hogrebe, W. (org.). Fichtes Wissenschaftslehre 1794. Philosophische Resonanzen. Frankfurt: Suhrkamp, 1995. 
O ponto de vista do agir, que com este resultado se torna o assunto próprio da abordagem fichtiana, tem de incluir alguma noção da própria liberdade. Por isso a questão de que conceito de liberdade é fundamental para a auto-referência prática tornase central para os passos seguintes da exposição fichtiana. Parece plausível voltar-se neste ponto ao pensamento, indispensável para o nosso agir, de que somos capazes de escolher fins, adotandoos pela própria decisão. Fichte denomina a liberdade concebida como capacidade de escolher de "liberdade material" e, adotando os termos da discussão filosófica da sua época, de liberdade do arbítrio (Freiheit der Willkür). ${ }^{12}$ E Fichte de fato se volta para a questão das condições sob as quais fins podem ser escolhidos, para explicitar o conceito de liberdade que é fundamental para a autoreferência prática. No entanto, subjaz a isso uma intenção crítica, pois Fichte pretende mostrar que a concepção da liberdade de escolha, embora seja indispensável para o nosso agir, não pode ser o conceito fundamental de liberdade na auto-referência prática. $\mathrm{O}$ conceito de liberdade de escolha, Fichte argumenta, depende de pressuposições, de modo tal que não pode ser reconhecido como o conceito fundamental de liberdade. É assim que o conceito de liberdade transcendental, ligado ao de vontade pura, é estabelecido no argumento fichtiano como o sentido de liberdade que é fundamental para a auto-referência prática. ${ }^{13}$

A análise crítica da liberdade de escolha proposta por Fichte visa, nos seus primeiros passos, destacar a estrutura do conhecimento empírico sem o qual a escolha de fins não seria possível. É nesse contexto que os conceitos de "impulso" e "sentimento" têm seu lugar, pois a consideração de fins possíveis exige o conhecimento dos próprios impulsos: só se apresentam para uma pessoa

12. Cf. Fichte, J. G. Wissenschaftslehre nova methodo. Kollegnachschrift K. Chr. Fr. Krause, pp. 46 e 158.

13. Com essa argumentação, Fichte formula a sua posição na discussão sobre o conceito de liberdade do arbítrio, que surgira a partir do segundo volume das Cartas sobre a Filosofia Kantiana de Reinhold, Leipzig 1792 (cf., em particular, pp. 262 ss.) e cujos principais autores eram, além de Reinhold, K. Chr. E. Schmid e K. F. Creuzer. Fichte entrara nesta discussão já com a sua resenha de Creuzer em 1793. 
como fins possíveis aqueles estados de coisas que satisfazem seus impulsos. O conhecimento dos próprios impulsos, por sua vez, é inseparável do conhecimento de situações objetivas - são estas que consideramos as causas do fato de que alguns dos próprios impulsos ainda não estão satisfeitos. Portanto, a contemplação de fins possíveis pressupõe a referência a uma realidade independente, que nos delimita e que tem de ser transformada para determinados impulsos poderem ser satisfeitos. Conceitos de fins são essencialmente conceitos de transformações das condições objetivas. ${ }^{14}$

Esse resultado significa que o exercício da liberdade de escolha pressupõe o conhecimento do estado de coisas objetivamente dado e, com isso, uma relação teórica com o mundo. No entanto, segundo Fichte, vale igualmente a inversão desta proposição: o conhecimento empírico do mundo exige agir e, com isso, a intencionalidade prática. Não é possível construir uma imagem objetiva do mundo pelo mero intuir e pensar, mas somente ao movimentarmo-nos como agentes no mundo. Assim, argumenta Fichte, a determinação objetiva de distâncias espaciais é possibilitada por movimentos do sujeito cognoscente no espaço. ${ }^{15}$ Este resultado é decisivo para a estratégia dominante na análise fichtiana das condições da liberdade de escolha. O exercício da liberdade do arbítrio e a referência a estados de coisas objetivos se pressupõem mutuamente um ao outro, resultando em um círculo no qual, segundo Fichte, fica enredada qualquer teoria da auto-referência prática que considera fundamental o conceito de liberdade de escolha. Para resolver o círculo, conclui Fichte, é preciso introduzir um conceito de liberdade que inclui o aspecto de uma objetividade delimitadora. Segundo isso, a liberdade tem de ser concebida como possuindo uma determinação objetiva que nos delimite. Assim, Fichte diz que o conceito de liberdade que é fundamental para a auto-referência prática envolve uma "determinação da liberdade mesma”. ${ }^{16}$ No entanto, esta argumentação não é convincente, pois

14. Cf. Fichte, J. G. Wissenschaftslehre nova methodo. Kollegnachschrift K. Chr. Fr. Krause, pp. 66 e ss.

15. Cf. Idem, pp. 117 e ss.

16. Cf. Idem, p. 140. 
não é claro em que medida a mútua relação pressuposicional entre o nosso querer e o conhecimento de condições objetivas exige uma terceira instância na qual os dois aspectos, liberdade e objetividade delimitadora, estão unidos. Seria mais plausível concluir que a consciência da liberdade e o conhecimento empírico do mundo são dois aspectos intrinsecamente entrelaçados da nossa consciência que só podem surgir em conjunto. No entanto, mesmo que a argumentação de Fichte nesse ponto não seja satisfatória, com a noção de uma "delimitação da liberdade mesma" Fichte introduz uma concepção importante para a compreensão da auto-referência prática.

Fichte caracteriza o aspecto em consideração mais precisamente como uma "exigência" na qual uma pessoa vê o seu "caráter principal". ${ }^{17}$ Assim, Fichte refere-se aqui ao status normativo da autoconcepção que é fundamental para a compreensão que uma pessoa tem da própria identidade. O modo como pessoas concebem sua identidade é inseparável de uma concepção do que devem ser e, com isso, da noção de que o seu agir está submetido a exigências. É do ponto de vista de uma tal autoconcepção que pessoas avaliam os seus impulsos e os fins possíveis determinados por eles. Segundo isso, não seria apropriado conceber a liberdade de uma pessoa meramente como liberdade de escolha. Em vez disso, o exercício da liberdade de escolha é tal que nele a identidade prática da pessoa faz-se valer. Assim, liberdade no sentido fundamental é a capacidade da pessoa de corresponder nas suas decisões às exigências que ela considera essencialmente ligadas à sua identidade. Com isso fica compreensível em que medida o introduzido conceito de liberdade envolve uma síntese de "liberdade" e "delimitação". O agir livre envolve essencialmente o aspecto de que as próprias escolhas são orientadas pelas exigências delimitadoras que estão ligadas à própria identidade. Portanto, ele inclui um distanciamento em relação àqueles impulsos cuja satisfação seria incompatível com estas exigências. Assim, a noção fichtiana da unidade de liberdade e delimitação expressa a idéia de

17. Cf. Idem, p. 148. 
que decisões livres são necessariamente executadas a partir de uma autoconcepção normativa.

Fichte denomina a exigência à qual a conscência da própria identidade se refere de "vontade pura" e de "imperativo categórico". ${ }^{18}$ Com isso, ele introduz termos centrais da ética kantiana na explicitação da identidade prática de pessoas. No entanto, não é objetivo de Fichte justificar nesse ponto da argumentação um determinado princípio da moral. Os dois termos servem aqui para referir-se a aspectos da identidade prática de pessoas. Uma exigência que é concebida como inseparável da própria identidade (como o próprio "caráter principal") não significa para uma pessoa uma delimitação que the seja externa; em vez disso, ela tem de ser considerada como determinação fundamental da própria vontade. A pessoa não pode entender esta determinação superordenada da sua vontade como resultado das suas escolhas, visto que ela subjaz às suas decisões, sendo, por assim dizer, a sua regra. No entanto, um querer anterior às próprias decisões, que determine o modo como uma pessoa se relaciona com seus impulsos, pode ser denominado "vontade pura". Tal querer é ao mesmo tempo um "imperativo categórico", pois submete decisões a uma exigência que não surge em função de impulsos dados ou de fins arbitrariamente escolhidos, mas constitui o fundamento a partir do qual, para a pessoa, fins determinados devem ser escolhidos.

Fichte introduz essa concepção, na Doutrina da Ciência nova methodo, como resultado de uma argumentação da qual foi dito que não é convincente. E que também tem de ser avaliada como insuficiente sob um aspecto metodológico, pois estabelece a concepção da identidade normativa a partir de uma perspectiva externa à da consciência do agente, a saber, como solução de um problema teórico de circularidade. No entanto, para entender a condição da auto-referência prática, é preciso entrar no seu próprio ponto de vista. Assim, a concepção fichtiana só pode ser suficientemente fundada por uma argumentação que evidencia a necessidade de identificar-se com uma exigência delimitadora a partir do ponto de vista do agente. A exposição de Fichte de fato aponta para um

18. Cf. Idem, pp. $142-3$. 
argumento que cumpre essa exigência. Numa nota que se refere ao argumento do círculo encontra-se o seguinte raciocínio:

Todo o meu agir é uma passagem da determinabilidade para a determinação, portanto deve existir algo ao qual a transição se atém; tem de existir algo contínuo e perdurante; procuramos e encontramos isso como o objeto imediato da consciência; e esta determinação da vontade pura é o princípio da explicação de toda a consciência. ${ }^{19}$

$\mathrm{O}$ argumento esboçado nessa passagem parte do fato de que agimos com base na consciência de que escolhemos os nossos fins. Fichte descreve a escolha como uma passagem (Überschweben) da contemplação ainda indecidida de possibilidades (da "determinabilidade") à direção do agir para um determinado fim. O aspecto decisivo para o argumento está na observação de que a escolha exige a consciência de uma instância que continuamente permanece durante tais passagens. Com isso, a necessidade de uma consciência da própria identidade que se estenda pelos atos de escolha torna-se central. A questão norteadora do argumento fichtiano é a de como uma pessoa pode formar uma consciência de sua identidade que tenha um conteúdo determinado. Obviamente, a consciência da própria liberdade de escolha não fornece uma base suficiente para isso. $\mathrm{Na}$ medida em que um sujeito atribui a si mesmo a capacidade de arbitrariamente adotar opções como fins, ele não concebe determinação alguma como essencial para si. Assim, a consciência da liberdade de escolha não oferece resposta alguma à pergunta sobre que pessoa sou eu - à pergunta que diz respeito à própria identidade.

Neste ponto, Fichte introduz a tese de que um agente pode conceber a sua identidade em todas as suas decisões apenas como a permanência de um querer que é essencial para ele. Portanto, uma pessoa tem de possuir a consciência de uma identidade volitiva. No entanto, o querer constitutivo para a própria identidade tem de ser concebido como anterior às próprias decisões - como um querer pelo qual todas as escolhas de fins se orientam. Assim,

19. Idem, p. 151 (tradução do autor). 
é a partir da identidade volitiva de pessoas que se entende por que determinadas escolhas são "certas" e importantes para elas. Neste sentido, a passagem para um determinado fim tem de "aterse" à identidade. Com isso, Fichte estabelece a conclusão de que a identidade de pessoas é dada por uma exigência delimitadora com a qual a pessoa se identifica. Numa abordagem acerca das condições da consciência prática da identidade surge, como resultado, justamente aquela concepção da "vontade pura" que Fichte já introduzira no argumento do círculo. No entanto, é somente com este segundo argumento que Fichte introduz a concepção da identidade volitiva de pessoas a partir do ponto de vista do próprio agir, como uma condição intrínseca de escolhas conscientes.

Como foi observado acima, Fichte expressa seu resultado com termos da ética kantiana: ao querer de ordem superior, que é constitutivo para a identidade prática da pessoa, ele chama de "vontade pura"; e à exigência normativa a que aquele submete as ações Fichte denomina "categórica", porque não depende das escolhas da pessoa. De fato existe uma correspondência entre a estrutura da vontade das pessoas, como descrita por Fichte, e a da vontade moral conforme concebida por Kant: a concepção kantiana da autonomia moral também se refere a um querer que é, ao mesmo tempo, um dever. E o conceito kantiano de liberdade diz respeito à capacidade, distinta da liberdade de escolha, de cumprir este dever. No entanto, é importante notar também a diferença entre as abordagens de Kant e Fichte, que fica clara quando o último diz que sua concepção não serve para fundar "uma determinada moral". Isso seria a tarefa de uma "Doutrina dos Costumes", isto é, da ética, mas não é o propósito daquela análise da auto-referencia prática que, segundo Fichte, faz parte da fundamentação de toda a filosofia. ${ }^{20}$

Assim, Fichte entende a exposição da identidade normativa de pessoas como sistematicamente anterior a qualquer fundamentação de uma ética especifica. Os termos kantianos, portanto, na exposição da consciência prática da identidade, ainda não têm

20. Cf. Fichte, J. G. Wissenschaftslehre nova methodo. Kollegnachschrift K. Chr. Fr. Krause, p. 143 (tradução do autor). 
nenhuma significação que envolva a aceitação da ética kantiana. Que a exigência constitutiva da identidade seja "categórica" não implica que ela possui a validade universal que caracteriza o princípio kantiano da razão prática pura. Em vez disso, categoridade no sentido aqui relevante é uma função da identidade volitiva: na medida em que uma exigência está intrinsicamente ligada à auto-concepção da pessoa, ela constitui o último horizonte da orientação de tal pessoa - a pessoa não possui um ponto de vista a partir do qual pudesse criticá-la ou delimitá-la por princípios de ordem superior. Ser "categórico", nesses termos, é compatível com a particularidade. Assim, Fichte vincula na sua ética o conceito de identidade normativa com o conceito de individualidade moral, ou seja, com a idéia de um particular papel (ou destino) moral do indivíduo na comunidade. ${ }^{21}$ Portanto, fica indecidido em que medida a auto-concepção que é constitutiva da identidade de uma pessoa tem de ligar-se a normas universalmente validas, questão à qual voltaremos adiante.

\section{A contribuição fichtiana e a análise contemporânea do conceito de pessoa}

Como se mostrou acima, a Doutrina da Ciência nova methodo envolve uma concepção da auto-referência prática que visa esclarecer porque pessoas possuem uma autoconcepção que está intrinsecamente ligada a um "dever", estabelecendo a identidade normativa como objeto de uma abordagem própria. No que segue, pretende-se mostrar que Fichte, com isso, antecipou uma concepção que se tornou central na discussão mais recente sobre o conceito de pessoa.

Fundamental para tal discussão é a análise do conceito de pessoa sugerida por Harry Frankfurt. $\mathrm{O}$ ponto de partida de Frankfurt - em seu clássico artigo "Freedom of the Will and the

21. Cf. Fichte, J. G. Das System der Sittenlehre. In: ___ Gesamtausgabe der Bayerischen Akademie der Wissenschaften. vol. I/5. Stuttgart: FrommannHolzboog, 1962, pp. 229 e ss. 
Concept of a Person" ${ }^{22}$ - foi uma análise do conceito de pessoa segundo a qual este se refere a uma determinada estrutura da vontade: o que caracteriza as pessoas é o fato de não possuírem apenas volições de primeira ordem, que são dirigidas para objetos ou estados a serem realizados pelo agir. Além delas, pessoas têm volições de segunda ordem que são dirigidas para os motivos presentes na primeira, submetendo-os a uma avaliação. Assim, pessoas possuem a capacidade de distanciar-se criticamente dos seus motivos de primeira ordem. Ainda que todos estes, num certo sentido, pertençam à pessoa, esta não se identifica com todos eles. Assim, o ponto de partida de Frankfurt na análise do conceito de pessoa foi a idéia do autocontrole volitivo como característica de pessoas expressa em termos de volições de duas ordens.

No entanto, esse resultado levanta a questão de por que volições de segunda ordem possuem tal importância para uma pessoa, delimitando a esfera dos motivos de primeira ordem com os quais ela se identifica. Tem de haver alguma ligação entre as volições de segunda ordem e a identidade da pessoa a partir da qual tal importância possa ser entendida.

Assim, nos trabalhos posteriores àquele artigo, Frankfurt ampliou a sua abordagem ao discutir o modo como a identidade de uma pessoa se constitui. ${ }^{23} \mathrm{O}$ ponto de partida foi a noção comum de que somos capazes de tomar as nossas próprias decisões. É essa a concepção que subjaz à idéia de um agir e de uma vida autodeterminada. Frankfurt observa que a idéia da autodeterminação não deve ser confundida com a de uma liberdade não-delimitada de escolha. Esta, ao contrário, implica que a pessoa é, por assim dizer, um quadro vazio que poderia adotar igualmente qualquer opção. Mas neste caso as decisões seriam arbitrárias, e não autodeterminadas. A idéia de decisões determinadas pela própria pessoa pressupõe

22. Frankfurt, H. "Freedom of the Will and the Concept of a Person". In: The Journal of Philosophy 68 (1971), pp. 5-20.

23. Cf., em particular, os artigos reunidos em Frankfurt, H. The Importance of what we care about. Philosophical Essays. Cambridge: Cambridge University Press, 1988; e __. "On the Usefulness of Final Ends". In: Iyyun. The Jerusalem Philosophical Quarterly 41, 1992, pp. 3-19. 
que ela possui uma identidade que subjaz às decisões que toma e que se expressa nelas. Sem a concepção de uma tal identidade, não seria compreensível a afirmação de que as decisões remontam à "pessoa mesma". Isso pressupõe que esta já seja algo determinado antes das decisões, possuindo uma identidade que as oriente.

É neste ponto que a concepção da identidade volitiva de pessoas entra na análise de Frankfurt: a identidade da pessoa, para orientar as suas escolhas, deve ser constituída por volições de ordem superior que delimitam as escolhas aceitas por ela. Tais volições - por constituírem a identidade da pessoa - não podem ser entendidas por ela como resultado das escolhas que toma. Assim, a pessoa considera-se a si mesma como submetida a elas nas suas decisões: há nelas uma exigência que é dada pelo que ela é essencialmente. Frankfurt fala, por isso, do caráter "categórico" que possuem as volições de segunda ordem envolvidas na identidade da pessoa. Ao mesmo tempo, no entanto, Frankfurt enfatiza a particularidade da identidade volitiva: ela constitui-se pelo que ele chama de caring (preocupação), isto é, a dedicação a algo para que a pessoa dirige o seu agir - pode ser, por exemplo, uma outra pessoa, os valores de uma tradição ou um ideal utopista. De qualquer modo, do fato de uma pessoa encontrar a sua identidade na dedicação a um determinado fim não se segue que outras pessoas devam fazer o mesmo. Em virtude de sua identidade volitiva, portanto, as pessoas consideram-se a si mesmas como submetidas a exigências que são particulares, embora para elas categóricas.

Com isso, evidencia-se a afinidade entre a análise de Frankfurt e a concepção fichtiana da identidade prática de pessoas: ambos adotam a concepção da identidade volitiva de pessoas. Ambos concebem essa identidade como uma determinação de ordem superior proveniente da vontade que submete as escolhas da pessoa a uma restrição auto-imposta. Em ambas as posições surge, como conseqüência disso, a concepção de uma categoridade envolvida no ponto de vista da pessoa. E ambos, finalmente, estabelecem esta concepção numa crítica da noção de liberdade como faculdade de escolher, introduzindo a identidade volitiva como o próprio ponto de partida para a compreensão adequada de liberdade. Portanto, a posição de Frankfurt pode ser considerada uma reformulação 
contemporânea do resultado da análise fichtiana da auto-referência prática de pessoas.

No entanto, é preciso destacar também uma diferença entre as concepções de Fichte e Frankfurt que diz respeito ao caráter particular do conteúdo normativo ligado à autoconcepção de pessoas. Segundo Frankfurt, a identidade prática de pessoas é definitivamente particular. Assim, pessoas podem adotar qualquer valor ou ideal (ou melhor, qualquer concepção que considerem um valor ou ideal) como essencial para si, definindo assim que tipo de pessoa são. Com isso, a identidade prática em Frankfurt não tem nenhuma ligação intrínseca com uma racionalidade universal - com a moralidade no sentido kantiano. Fichte, ao contrário, defende que a autoconcepção normativa de pessoas está essencialmente vinculada a um ideal de autodeterminação da humanidade, de tal modo que a pessoa concebe a efetuação da sua identidade como a sua contribuição para esse fim universal. A identidade normativa no sentido fichtiano é particular, mas é uma identidade moral da pessoa. Com isso, Fichte introduziu o conceito de individualidade moral, que, segundo ele, não pode ser simplesmente reduzido à aplicação de um princípio formal às situações particulares de uma pessoa. Fichte manteve assim, na sua concepção da identidade normativa de pessoas, uma ligação positiva com a ética kantiana, enfatizando, no entanto, o caráter individual da identidade moral de uma maneira que não corresponde mais à ética kantiana. $\mathrm{Na}$ literatura mais recente, foi Christian Korsgaard quem se voltou para a vinculação entre a identidade normativa de pessoas e a idéia de uma razão universal, argumentanto que a identidade volitiva das pessoas, no seu nível fundamental, tem de ser concebida como uma identidade moral no sentido kantiano. ${ }^{24}$ Segundo Korsgaard, este argumento é decisivo para a justificação da ética kantiana. A partir da posição de Korsgaard, assim, tornou-se presente, na discussão contemporânea, a tese ligada à análise da auto-referência prática na Doutrina da Ciência nova methodo, a saber, que a concepção pré-ética da identidade volitiva de pessoas não apenas é um campo próprio da análise

24. Cf. Korsgaard, C. The Sources of Normativity. Cambridge: Cambridge University Press, 1996. 
filosófica, mas também fornece o pano de fundo conceitual a partir do qual questões da fundamentação da ética têm de ser discutidas.

\section{BIBLIOGRAFIA:}

FICHTE, J. G. Das System der Sittenlebre. In: Gesamtausgabe der Bayerischen Akademie der Wissenschaften. Vol. I/5. Stuttgart: Frommann-Holzboog, 1962.

- "Neue Bearbeitung der Wissenschaftslehre". In: Gesamtausgabe der Bayerischen Akademie der Wissenschaften. vol. II/5. Stuttgart: Frommann-Holzboog, 1962.

. Wissenschaftslehre nova methodo. Kollegnachschrift K. Chr. Fr. Krause. Org. de E. Fuchs. Hamburgo: F. Meiner, 1982.

. A Doutrina-Da-Ciência de 1794 e Outros Escritos. Trad. de Rubens Rodrigues Torres Filho. São Paulo: Abril Cultural, 1984.

FRANKFURT, H. "Freedom of the Will and the Concept of a Person". In: The Journal of Philosophy 68 (1971), pp. 5-20. The Importance of what we care about. Philosophical Essays. Cambridge: Cambridge University Press, 1988. "On the Usefulness of Final Ends". In: Iyyun. The Jerusalem Philosophical Quarterly 41, 1992, pp. 3-19.

HENRICH, D. "Fichtes ursprüngliche Einsicht". In: CRAMER, W.; (orgs.). Subjektivität und Metaphysik. Frankfurt: V. Klostermann, 1966.

KANT, I. Fundamentação da Metafisica dos Costumes. Trad. de F. Gottschalk. Lisboa: Edições 70, 2003.

NEUHOUSER, F. Fichte's Theory of Subjectivity. Cambridge: Cambridge University Press, 1990.

STOLZENBERG, J. "Fichtes Begriff des praktischen Selbstbewusstseins”. In:Hogrebe,W.(org.). Fichtes Wissenschaftslebre 1794. Philosophische Resonanzen. Frankfurt: Suhrkamp, 1995. 